\author{
Marquette University \\ e-Publications@Marquette
}

$10-2013$

\title{
Learning from Teen Childbearing Experiences of Close Friends: Evidence Using Miscarriages as a Natural Experiment
}

Olga Yakusheva

Marquette University, olga.yakusheva@marquette.edu

Jason Fletcher

University of Wisconsin - Madison

Follow this and additional works at: https://epublications.marquette.edu/econ_fac

Part of the Economics Commons

\section{Recommended Citation}

Yakusheva, Olga and Fletcher, Jason, "Learning from Teen Childbearing Experiences of Close Friends: Evidence Using Miscarriages as a Natural Experiment" (2013). Economics Faculty Research and Publications. 386.

https://epublications.marquette.edu/econ_fac/386 
LEARNING FROM TEEN CHILDBEARING EXPERIENCES OF CLOSE FRIENDS:

EVIDENCE USING MISCARRIAGES AS A NATURAL EXPERIMENT

\author{
Olga Yakusheva ${ }^{\mathrm{a}}$, Jason Fletcher ${ }^{\mathrm{b}}$ \\ ${ }^{\mathrm{a}}$ Department of Economics, College of Business, Marquette University, ${ }^{\mathrm{b}}$ Robert M. La Follett \\ School of Public Affairs, University of Wisconsin-Madison
}

\begin{abstract}
We examine peer effects in teen childbearing among close friends, using miscarriages as a natural experiment. We use 775 women from the core sample of Add Health who had a friend with a teen pregnancy. We find a sizable negative treatment effect - a close friend's teen birth is associated with a 6 percentage point reduction in the likelihood of own teen pregnancy and childbearing. There is evidence that this effect operates through a learning mechanism by changing beliefs regarding early childbearing. Effects of teen pregnancy prevention policies may be partially offset by reductions in the opportunities for social learning.
\end{abstract}

JEL Codes: I18, J13

Corresponding Author: Yakusheva; Mailing Address: 606 N. $13^{\text {th }}$ Street, Milwaukee, WI 53201; email: olga.yakusheva@marquette.edu. 


\section{Introduction}

Teenage childbearing is associated with a host of negative consequences for teen mother and their children. Each year, close to a third of a million US girls age 15 through 19 have a child (Martin et al. 2010), and almost three quarters of these births result from pregnancies that were unintended (Harrison et al. 2012). Federal programs aimed at preventing teen pregnancy were projected to cost the US government close to \$200 million in 2010 alone (Department of Health and Human Services 2009) - yet the teenage birth rate in the United States remains the highest among all developed countries (United Nations, 2010).

A growing body of empirical literature points to the importance of a teen's social environment as a determinant of a range of health behaviors and outcomes, including teen pregnancy and childbirth. Most of the existing studies find evidence of positive peer influence, meaning that adolescents engage in behaviors similar to those of their peers, and there are two reasons why this may be the case. First, theories of the mechanisms underlying peer influenceknowledge externalities (i.e. learning from peers), network externalities (e.g. increasing returns to scale in joint childrearing with peers), and social norms (e.g. peer childbearing reducing the social stigma of teen childbirth) - all suggest that behaviors are likely to be positively correlated within peer groups. Second, empirical estimates of peer effects can be biased upward due to, for example, unobserved peer selection or shared environmental influences, and few of the existing studies offer research designs capable of credibly isolating the true causal peer effect from these confounding influences.

The key contribution of the present study is the novel finding of a negative local treatment effect of teen childbirth of a close friend on own likelihood of teen pregnancy and childbearing. While rarely found in empirical research, negative correlations in peer behaviors 
have some compelling theoretical motivations, one of which is the knowledge externality generated from learning the consequences of peer behaviors ${ }^{1}$. Indeed, in some behaviors, such as teen childbearing, we might imagine the possibility of a large amount of learning about the difficulties of being a teen mother if a high school friend has a child. This knowledge externality may lead to negative correlations in peer behaviors within peer groups. We present evidence consistent with the notion that the negative effect appears to operate through a learning mechanism by changing beliefs about teen motherhood and reducing pregnancy and childbearing. Our finding is highly policy relevant because it suggests that policies that are successful in reducing teenage childbearing may be partially offset in their overall effects due to the unintended negative spill-over effect of limiting learning opportunities from peer's childbearing experiences (i.e. reducing knowledge externalities).

\section{Background Literature}

Negative consequences of teen childbearing are well documented and include, among others, lower educational attainment and increased participation in welfare programs (Angrist and Evans 1996; Chevalier and Viitanen 2003; Fletcher and Wolfe 2009; Levine and Painter 2003). The children of teen mothers are at a higher risk of premature birth and low birth weight, reduced educational attainment, and they are more likely to be incarcerated as adults (Martin et al. 2010; Mathews and MacDorman 2010). Furthermore, the daughters of teen mothers are significantly more likely to have a teen childbirth themselves (Manlove et al. 2008; Hoffman and Scher 2008).

\footnotetext{
${ }^{1}$ Network externalities could also generate negative peer correlations in behavior if the behaviors were subject to congestion effects.
} 
Studies found that adolescents may be susceptible to peer influence along multiple margins of fertility choice, from initiation of sexual activity (Fletcher 2007; Richards-Shubik 2011; Ali and Dwyer 2011), to pregnancy (Evans et al. 1992; Fletcher and Yakusheva 2012), to, ultimately, childbearing (Case and Katz 1991; Kuziemko 2006; Monstad et al. 2011). This tendency toward adoption of fertility-related behaviors of peers was found to exist in a variety of peer group settings including neighborhoods (Case and Katz 1991; Evans et al. 1992), classmates (Fletcher 2007; Richards-Shubik 2011; Fletcher and Yakusheva 2012), co-workers (Hensvik et al. 2011), siblings (Kuziemko 2006; Monstad et al. 2011), and close friends (Ali and Dwyer 2011).

Our understanding of the mechanism of social transmission of adolescent childbearing is, however, rather limited. Some peer effect studies argue for social norms as the leading mechanism behind social contagion in teen pregnancy, whereby exposure to high rates of adolescent pregnancy reduces the "stigma cost" of being a teenage mother (Case and Katz 1991; Fletcher and Yakusheva 2012). Evidence consistent with network externalities in peer influence (i.e. increase in the net benefit of childbearing when your peer has a child through, for example, economies of scale in joint childrearing) has also been documented by a small number of peer effect studies examining, for example, correlation in timing of childbearing among co-workers (Hensvik et al. 2011) and siblings (Kuziemko 2006). However, empirical evidence of the role of knowledge externalities as a conduit for peer influence in teen pregnancy, the key finding of this study, has been particularly limited in the literature. Only one study finds some evidence consistent with the notion of knowledge externalities between sisters (Kuziemko 2006). At the same time, a significant body of theoretical and conceptual developments on knowledge externalities exists outside of the peer effects literature, particularly in the context of 
contraceptive and other fertility information dissemination and its contribution to declining fertility and other demographic trends (Kohler et al. 2001; Munshi and Myaux 2006;

Montgomery and Casterline, 1996). While these mechanisms of peer influence are likely not mutually exclusive, being able to distinguish between them is key to designing successful teen pregnancy prevention policy.

The sign of the peer effect in fertility depends on the mechanism through which peer influence is transmitted. Existing theories and empirical finding on social norms and network externalities typically argue for an propensity of an individual toward choosing behaviors similar to those of their peers, or conformity with peer behaviors, even in the face of a negative payoff (Banerjee 1992; Bikhchandani et al.1998; Case and Katz 1991; Hensvik et al. 2011; RichardsShubik 2011; Fletcher and Yakusheva 2012). However, when correlation in peer behaviors occurs through the learning mechanism, its sign is theoretically undetermined. Schlag (1998) demonstrates situations where the optimal choice under uncertainty stipulates to not imitate behaviors of individuals whose realized outcomes are worse than oneself and imitate those whose realized outcomes are better (with probability proportional to the difference in realizations). Under this rule, observing a friend have a teen childbirth will increase a woman's likelihood of becoming a teen mother herself if she perceives her friend's fertility experience as being positive and better than her own, and decrease her chances of becoming a teen mother if she views it as having substantial negative consequences.

Difficulties in establishing the mechanism of peer influence aside, estimating the magnitude of reduced-form peer influence presents a significant empirical challenge in itself as the causal peer effect is often muddled by unobserved peer selection, simultaneity of peer influence, and exposure to common contextual effects (Manski 1993). Existing studies use a 
number of empirical approaches from variations of combined fixed effects and instrumental variable models (Evans et al. 1992; Richards-Shubik 2011; Ali and Dwyer 2011; Fletcher 2007; Fletcher and Yakusheva 2012), to exploiting the timing of outcomes (Kuziemko 2006; Hensvik et al. 2011). One recent study utilizes a natural experiment, a school-level educational reform in Norway, to measure the impact of the intervention targeting the older sister on the fertility outcomes of the younger sister (Monstad et al. 2011).

This paper relies on a natural experiment, friend's miscarriage, to measure the impact of a quasi-random fertility shock to the peer on the fertility outcomes (pregnancy, childbearing) of the focus individual. Our identifying assumption is that conditional on a friend's pregnancy, the occurrence of a friend's miscarriage is an exogenous fertility shock that is uncorrelated with the unobservable factors. Under this assumption, miscarriage-based estimates of peer influence are free from the selection bias that many earlier peer effects studies struggle with. We deal with the reflection bias by lagging the model, and we control for school-level fertility measures to account for shared environment bias. If the assumption of exogeneity of miscarriage is violated, our estimates would most likely reflect a lower-bound effect because selection, reflection and shared environment biases produce positive correlations in fertility behaviors.

Use of miscarriage as a strategy to partition random variation in childbirth from systematic variation due to unobservable factors was pioneered by Hotz et al. $(1997,2005)$. Since then, this identification strategy has been used to measure the impact of a teen parenthood on a host of mother's subsequent outcomes including educational attainment, earnings, and welfare dependence (Hotz et al. 2005; Ashcraft and Lang 2006; Fletcher and Wolfe 2009)².

\footnotetext{
${ }^{2}$ Fletcher and Wolfe (in press) utilize miscarriages to examine the impact of a teen birth on the teen father. They compare the outcomes of male adolescents whose partner had a teen childbirth
} 
Although miscarriage has been used in a number of studies to examine the effects of teen childbearing on own and child outcomes, our paper is unique in utilizing the fertility shocks of miscarriage of friends to examine peer effects in fertility decisions.

\section{Miscarriage as a natural experiment}

Miscarriage, also referred to as spontaneous abortion, is defined as loss of the intrauterine product prior to the viability of the fetus, usually before the 24 th week of pregnancy (Oats and Abraham 1995). According to the American College of Obstetricians and Gynecologists, 10-25\% of all known pregnancies end in miscarriage (American College of Obstetricians and Gynecologists 2011). This number is likely higher because many miscarriages happen very early, before the woman knows she is pregnant.

While the etiology of miscarriage varies, chromosomal abnormalities is the most common factor and studies have found some chromosomal abnormality in $50-80 \%$ of all examined first trimester losses (American College of Obstetricians and Gynecologists 2011; Royal College of Obstetricians 1997; Kajii et al. 1980; Eiben et al, 1990; Hogge et al. 2003; Philipp et al. 2003). Other frequent risk factors include anatomical or immunological abnormalities that can cause the mother's body to reject the pregnancy (Oats and Abraham 1995; Cramer and Wise 2000; Regan and Rai 2000; Lerner 2003). Infections, as well as certain systemic medical illnesses (diabetes, thyroid disease, lupus), are also believed to cause miscarriage, with as many as a half of pregnancies to women with diabetes ending in miscarriage (Oats and Abraham 1995; Cramer and Wise 2000; McDonald and Chambers 2000; Lerner 2003; Matovina et al. 2004). There is also a tentative link between certain environmental factors (e.g.

to those whose partner's teen pregnancy ended in a miscarriage and find a modest negative effect on educational attainment. 
pollutants) and miscarriage risk (Green et al. 2009; Sunil 2011). Lastly, substance abuse (cigarette, alcohol, drugs) has been associated with increased miscarriage risk (Baba et al. 2011; Venners et al. 2004; Oats and Abraham 1995; Lerner 2003); however the 2004 Surgeon General's report concluded that the evidence is insufficient to infer a causal relationship between smoking and miscarriage (U. S. Department of Health and Human Services 2004).

While close to 70 percent of all miscarriages happen before the $12^{\text {th }}$ week of pregnancy, the timing of miscarriage varies (see Figure 1.A). Cytogenetic analysis studies have shown that chromosomal abnormalities can cause spontaneous miscarriage at a range of gestational ages accounting for over 50 percent of all pregnancies lost before week 12 (with the peak prevalence at weeks 10-11) and over 35 percent of all pregnancies lost after week 12 (Kajii et al. 1980; Eiben et al. 1990; Hogge et al. 2003; Philipp et al. 2003). Second trimester losses (after week 12) are less frequent and more likely to be caused by developmental (non-chromosomal) fetal abnormalities (e.g. spina bifida), as well as by maternal anatomic factors, immunologic factors, and infection (Cramer and Wise 2000; McDonald and Chambers 2000; Matovina et al. 2004; Thomas and Tiu 2007).

Our identification strategy relies on the assumption that miscarriages are correlated with the friend's childbearing status and uncorrelated with unobservable characteristics of the woman. While miscarriages resulting from chromosomal or anatomical abnormalities are plausibly exogenous, some of the other risk factors could violate our identifying assumption. For example, if women and their friends are exposed to the same environmental factor that put all of them at an increased risk of a miscarriage, the miscarriage-based estimate will be biased upward. In fact, Fletcher and Wolfe (2009) found evidence of systematic variation in miscarriage rates across communities and schools and demonstrated that miscarriage-based estimates of the impact 
of teen childbirth are reduced when this systematic variation is controlled for with communityor school-level fixed effects. Similar to Fletcher and Wolfe (2009), we find systematic variation in miscarriage rates across schools and control for school-level aggregate fertility outcomes (including miscarriage) in our analysis.

In addition to shared environmental factors, women who are at a higher risk of miscarriage due to underlying health issues (or because they engage in substance abuse) may choose friends with similar characteristics, in which case the estimates will also be subject to unobserved peer selection bias. Hotz et al. (1997) constructed bounds, presumably containing the true causal effect, based on a proportion of all miscarriages that are believed to be random, and found their estimates to be robust to potential non-randomness. However, this approach has been criticized on the grounds that the width of the bounds depends critically on the untestable assumption regarding the proportion of all miscarriages that are truly random vs. non-random.

In this study, we present a series of tests showing that, conditional on pregnancy, miscarriages are uncorrelated with a host of socioeconomic and demographic characteristics of the focus individual. Additionally, because we examine the impact on a woman's fertility of her friend's miscarriage, we are able to go a step further than the existing studies and explicitly test whether miscarriages are correlated among peers. If peer selection was driving our miscarriagebased results, this test would produce a significant positive correlation in the likelihood of a miscarriage between friends. We will show that conditional on friend's pregnancy and schoollevel aggregate fertility measures, miscarriages are not correlated between friends.

Another potential issue with using a miscarriage as an exogenous fertility shock is that some of the miscarriages may in fact be misreported elective abortions. Although the survey was administered in a way that is known to minimize the reporting bias, some women may still 
misreport abortions as miscarriages. For example, medical abortion, which is an alternative to surgical abortion and uses prescription abortifacient pharmaceutical drugs (commonly referred to as the abortion pill) before $9^{\text {th }}$ week of gestation, is often explained to patients as causing a miscarriage. ${ }^{3}$ Furthermore, the distinction between miscarriages and abortions may not be clearcut even if all miscarriages were correctly reported and truly random. The reason is that some miscarried pregnancies would have been electively terminated/aborted had the pregnancy not been miscarried (Ashcraft and Lang 2006; Fletcher and Wolfe 2009). Because, compared to teen moms, women who choose abortion tend to be of a higher socioeconomic status and have better outcomes, this potential contamination of the miscarriage group with abortions could introduce an upward bias in the estimate of the effect of a peer's childbirth on own probability of pregnancy and childbirth.

We present a test similar to the one described above where we show that miscarriages and abortions are conditionally uncorrelated among friends. Furthermore, following Ashcraft and Lang (2006) and Fletcher and Wolfe (2009) we exploit the timing of miscarriages (by focusing on late miscarriages after the $8^{\text {th }}, 10^{\text {th }}$, and $14^{\text {th }}$ week of pregnancy), with the idea that most elective abortion procedures are conducted before the $10^{\text {th }}$ week of gestation. According to miscarriage and abortion by week of gestation statistics (Hammerslough 1992), this approach could eliminate half of all abortions and 30 percent of all miscarriages by week 8 , over 80 percent of all abortions and 45 percent of all miscarriages by week 10, and virtually all abortions and 75 percent of all miscarriages by week 14 (Figures 1.A\&B). Therefore, focusing on later

\footnotetext{
${ }^{3}$ It has been estimated that about $17 \%$ of all abortions in the US are medical abortions. (Jones and Kooistra 2011)
} 
miscarriages allows us to examine pregnancy loss that is likely due to random chromosomal, developmental, or anatomical abnormalities.

\section{Data}

The data in this study come from the restricted version of the National Longitudinal Study of Adolescent Health (Add Health). Add Health is a school-based, longitudinal study of health-related behaviors of adolescents and their outcomes in young adulthood, stratified by region, urbanicity, school type, size, and ethnic mix. The survey was conducted in multiple waves. Wave I consists of an in-school questionnaire administered to close to 90,000 students and an in-home component administered to a subsample of about 20,000 students and their parents. The in-home cohort was followed up with a series of in-home surveys, approximately 1 year (Wave II), 6 years (Wave III), and 13 years (Wave IV) later. About 12,000 of Wave I inhome students comprise the main (core) sample that represents a nationally representative sample of adolescents in grades 7 through 12 in the US in 1994-1995 school year, and the rest are special oversamples (well-educated blacks, disabled, siblings, etc.). The present study uses the core sample without oversamples.

One of the distinct features of the Add Health survey is that it is designed to capture friendship data as completely as possible. Each respondent was asked to name their friends during the Wave I in-school and in-home surveys and during the Wave II in-home survey. In addition to the list of friend nominations, the survey is designed to capture the friendship rank, asking about the first friend first, and then asking for up to five male and up to five female friend nominations. The present study pools all three sets of female friend nominations, resulting in up to 15 possible friend nominations per individual. Both the nominating and the nominated individuals are included, regardless of whether or not the nominated individual reciprocated the 
nomination (i.e. the network ties are undirected). Duplicate nominations are removed after averaging out the within-nomination friendship rank if it varies. We create three measures based on the nomination data: number of nominations, friendship rank and whether or not the friendship nomination was reciprocated, to be used as controls for individual-level friend network structure.

Of the 12,105 core sample students surveyed in home at Wave I, approximately half were female and close to 4,500 women were followed at Wave III, when on average they were 22 years old. At Wave III, each participant was asked to complete a pregnancy history questionnaire, including information on the age at which each pregnancy ended, length of pregnancy, and the pregnancy outcome (live birth, abortion, miscarriage, and still birth). To maintain confidentiality and reduce reporting bias, paper questionnaires were not used for this portion of the interview; instead the respondent entered answers on a laptop computer in private, after the interviewer had left the room. We use the pregnancy history information to capture a complete set of fertility outcomes that occurred before age 20 for each woman, including all teen pregnancies and pregnancy resolutions (live births, miscarriage, or abortion).

We construct school-level aggregate measures of teen fertility (miscarriage, abortion, and birth) by computing the average prevalence of each outcome by school in the full Wave III female sample of over 6,000 observations (or the number of women experiencing a given outcome before age 20 over the total count of female observation for each school). Although using the full survey sample and not just our friendship-linked sample reduces the chance that our estimates will be subject to the negative bias that can arise from including these school-level averages in the regression model (Guryan et al. 2009), we compute these averages after excluding the focus individual and her friends. We also construct a set of other school-level 
demographic and socioeconomic controls (proportion of African Americans, parental income, mother's education, etc. $)^{4}$. The full list of variables used in our analysis and their descriptions are available in online supplementary materials (Appendix A).

A total of 2,430 women had at least one female friend who was also interviewed in Wave III. Because we focus on comparing women whose friends miscarried to those whose friends carried to term, we further restrict our sample by excluding 1,592 women whose friends did not have a teen pregnancy. As we discuss in more detail later, we further restrict our estimation sample by excluding 63 women who became pregnant prior to any of their friends (i.e. chronologically implausible peer effects). The remaining 775 women who had at least one friend with a teen pregnancy comprise our final sample, and 152 of these women had a friend whose teen pregnancy ended in a miscarriage. A total of 136 women had a teen pregnancy themselves, and 90 had a teen birth.

Table 1 presents descriptive statistics stratified by the friend's teen fertility status. Column 1 shows women who will be excluded from our analysis because none of their friends had a teen pregnancy, Column 2 shows women who had at least one friend with a teen pregnancy, and Column 3 shows our final estimation sample that excludes women who became pregnant prior to any of their peers. Note that this exclusion lowers the own fertility rates in Column (3) as compared to Column (2); however, none of the other variables are different between the last two columns. We do however observe large differences between women who did not have a friend with a teen pregnancy and women who did, at both the individual and the school level. Women with pregnant friends are almost 10 percentage points more likely to have a teen pregnancy themselves (24\% vs. $15 \%)$, and they are 6 percentage points more likely to have

\footnotetext{
${ }^{4}$ We do not exclude friends when computing these demographic and socioeconomic averages.
} 
a teen birth (16\% vs. $10 \%)$. However, they are also more likely to be of a minority status, have economically disadvantaged backgrounds, and come from schools with higher overall fertility rates, and these factors may be indicative of a higher propensity toward early childbearing regardless the childbearing experiences of friends. Isolating the causal flow of peer influence requires properly accounting for these confounding influences.

\section{Estimation}

The traditional approach to estimating peer effect utilizes a so called linear-in-means model that regresses the outcome of the focus individual (ego) on the average of the corresponding characteristic of the peers (alters), aggregated at some peer group-level. Pioneered by Case and Katz (1991), and further developed by Manski (1993, 1995, 2000), this approach has been used in a large number of peer effects studies (see for example Ali and Dwyer 2011, Bifulco et al. 2011; Fletcher and Yakusheva 2012, Yakusheva et al. 2011, Yakusheva et al. forthcoming). However, because our identification strategy is conditional on the friend's pregnancy, traditional linear-in-means model would not allow us to adequately model situations where the ego or the alter has multiple pregnancies. For example, a situation when an alter has two miscarriages prior to the ego's birth should be treated differently from a situation when only one of the alter's miscarriages is temporally relevant for the ego's birth (i.e. precedes it), and it should also be treated differently from a situation when the alter only has one miscarriage. The temporal structure of the events can become complex when the ego has multiple fertility outcomes and multiple alters with multiple fertility outcomes. Although a panel-data approach or survival analysis may appear to be a natural fit for these data, neither is appropriate in our case because of the cross-sectional nature of the identifying variation (egos with alters who had a 
birth versus egos with alters who had a miscarriage) and differences in the timing of the alters' pregnancies (see online supplementary materials, Appendix B).

We adopt an approach that is conceptually similar to the conventional linear-in-means model, but is notably more granular (see online supplementary materials, Appendix B). We link each individual (ego) in the data to each of her nominated friends (alters) who reports a teen pregnancy. We further expand this analysis to allow each alter's pregnancy outcome to affect the ego's outcome by linking pairs of ego and alter outcomes. For example, an ego with two alters who each have two pregnancies number four observations in our data. To avoid giving undue influence to egos with many alters with many pregnancies, we weight the data. We include only temporally-relevant pregnancies of the alters (i.e. pregnancies that happen prior to the ego's pregnancy) and do not estimate effects of future alter pregnancies, but instead use these results as a falsification exercise. The final sample has 1,490 “ego's fertility event $\times$ alter's fertility event" observations.

The study estimates the following lagged peer effects model (a detailed description of the regression model is provided in online supplementary materials, Appendix B):

$$
Y_{(t+1) i}=\mathrm{const}+\alpha M_{(t) j}+\beta A_{(t) j}+F_{i}{ }^{\prime} \gamma+F_{j}^{-t \prime} \delta+\bar{F}^{-j}{ }^{\prime} \rho+\phi K_{i}+R_{i j}{ }^{\prime} \varphi+X_{i}^{\prime} \theta+S_{i}{ }^{\prime} \lambda+\varepsilon_{i j}(1)
$$

Here, subscript $i$ denotes the ego, subscript $j$ denotes the alter, and $t+1$ and $t$ are the time periods when the ego's and the alter's fertility events occur, respectively. As such, $Y_{(t+1) i}$ is ego's own fertility outcome (no pregnancy/ miscarriage/ abortion/ birth) at some time period $t+1$ and variables $M_{(t) j}$ and $A_{(t) j}$ represent the alter's pregnancy outcome (miscarriage or abortion, birth is omitted) during some prior period $t$, controlling for ego's own fertility history $F_{i}$ (number of 
miscarriages, abortions, and births) prior to event $t+1 .{ }^{5}$ Note that the time-indexes, $t+1$ and $t$, are not associated with a particular cardinal time or periodicity, other than the ordinal understanding that time period $t+1$ is temporally preceded by time period $t$.

Most alters in our sample have only one pregnancy (the pregnancy that conditions the dyad into the sample), and as such, the resolution of this pregnancy is used as the focus event $t$ in the regression model (the average number of pregnancies per alter is 1.317 ). For alters with multiple temporally-relevant pregnancies, the resolution of each pregnancy is used as the focus event $t$ once and, each time, resolutions of the other temporally-relevant pregnancies of the alter (excluding the focus pregnancy $t$ ), $F_{j}^{-t}$, are controlled for, so as to ensure that the estimate of the focus pregnancy resolution is not confounded by resolutions of these other pregnancies of the alter.

Although most egos in our sample are only matched with one alter who has a pregnancy (average number of alters per ego is 1.262), cases where an ego is matched with multiple alters might cause our peer effect estimate to be biased due to spillovers in outcomes among alters. For example, if an ego has two alters who become pregnant, the pregnancy of the alter that happened first might affect the ego directly, as well as indirectly through the pregnancy of the second alter. In the presence of such spillovers, the estimate of the peer effect will incorrectly reflect individual-level elasticities and the corresponding social multiplier (Glaeser et al. 2003). To avoid this, we control for a vector of average temporally-relevant fertility outcomes

\footnotetext{
${ }^{5}$ For egos who did not get pregnant, one fertility event $\left(Y_{(t+1) i}=0\right)$ is matched to all of the alters' events and own prior fertility history variables are set to zero.
} 
of $i$ 's friends excluding the focus friend $j$ (average number of miscarriages, abortions, and births), $\bar{F}^{-j}$.

Other controls include ego $i$ 's number of friendship links $(K)$, a vector of friendship specific variables (friendship rank of alter $j$ as nominated by ego $i$ and a $0 / 1$ indicator for reciprocated nomination, $R$ ), ego $i$ 's observable characteristics, (age, African American, Hispanic, other non-white, age, parental income, two-parent family, mother's education, $X$ ), and school-level controls (percent African American, average parental income, average mother's education, percent two-parent families, percent teen miscarriage, percent teen abortion, percent teen birth, $S$ ). We weight all models using a product of the Add Health survey design Core 1 sampling weights and our constructed inverse frequency weights, and cluster standard errors at the individual level. We also implement standard adjustment for Add Health survey design that includes clustering at the school level and stratification by region. We use a multinomial logistic regression and compute average marginal effects.

Our coefficient of interest in model (1) is $\alpha$. If $\alpha$ is negatively related to ego's likelihood of having a live birth, this would be consistent with a positive childbearing peer effect, or conformity with peer behavior among friends, accounting for confounding due to selection, reflection, and common environmental influences. A positive significant coefficient of friend's miscarriage, on the other hand, would suggest that women with friends who had a teen childbirth are less likely to experience a teen pregnancy and childbirth themselves. Note that due to the use of inverse frequency weights, the magnitude of the coefficient represents the change in own probability of having a teen birth as the proportion of pregnant friends who give birth (as opposed to miscarry) changes from 0 to 1 , and is conceptually equivalent to the peer effect coefficient in the conventional linear-in-means model. 
We conduct two tests of the validity of our identifying assumption of exogeneity of miscarriages. Specifically, if miscarriages were non-random but rather caused by common environmental factors or correlated through unobserved peer selection, we would expect a positive significant coefficient of the friend's miscarriage variable in the own miscarriage equation. Additionally, if miscarriages were contaminated with abortions, we would expect a positive and significant cross-outcome effects, i.e. a positive association between a friend's abortion and own miscarriage.

Lastly, we attempt to examine a bit further the extent to which potential contamination of miscarriages with misreported and "would-be" abortions may be confounding our results, by restricting our sample to only pregnancies that lasted longer than 8,10 , and 14 weeks. Epidemiological studies show that more than a half of all elective abortions happen by week 8, three quarters happen by week 10, and virtually all elective abortions happen by week 14 (Figure 1.B). In our sample, $90 \%$ of all abortions were reported on or before the $14^{\text {th }}$ week of pregnancy. Restricting the sample in this way is likely to significantly reduce any confounding due to misreported abortions and spontaneous miscarriage of pregnancies that would have otherwise been electively terminated.

\section{Results}

Table 2 shows the results of the balancing tests where we regress an extensive set of socioeconomic and demographic characteristics of the ego on the miscarriage status of the alter. The balancing tests are consistent with the idea that women whose friends miscarried are very similar to women whose friends carried to term. Only one of the balancing tests produced a significant coefficient, which is expected for one out of every 20 tests at a .05 level. 
Additionally, the significant difference is in the network characteristic of the friendship link that has little impact on any of our results.

Table 3 shows our main set of results, using miscarriage to identify the impact of a friend's teen childbirth on own teen fertility. The columns represent the estimated average marginal effects for four outcomes of the dependent variable (no pregnancy/ miscarriage/ abortion/ childbirth), computed using the coefficient estimates from model (1). The results show a significant negative relationship between friend's teen birth and own childbirth. Specifically, friend's teen miscarriage is associated with a $5.8(\mathrm{p}<.10)$ percentage point reduction in own probability of a not becoming pregnant as a teen (i.e. friend's miscarriages are related to additional ego pregnancies) and a $6.2(\mathrm{p}<.01)$ percentage point increase in the probability of having a teen birth. This means that women whose friends had a teen birth were significantly less likely to have a teen pregnancy and childbirth themselves, as compared to women whose friend's pregnancy ended in a miscarriage. Note that this negative effect of a friend's teen birth on own teen fertility arises only after we condition on the friend's pregnancy status in Table 3, while the naïve examination of fertility outcomes in Table 1 shows a significant and positive correlation.

Some of the other important determinants of teen pregnancy and childbearing are the own past fertility history, race, mother's education, and school-level environment measures. African American women are significantly more likely to have a teen pregnancy and childbirth, as well as women with less educated mothers. Women exposed to high rates of teen childbearing at the school are, not surprisingly, more likely to have a teen pregnancy and childbirth. Lastly, there is a positive association between the likelihood of having a miscarriage and school-level socio- 
demographic and fertility measures, suggesting that unobserved socioeconomic or environmental factors common at the school level may systematically impact miscarriage rates. ${ }^{6}$,

${ }^{6}$ We also estimate our models without controls for school level aggregate fertility measures and after dropping schools with less than 100 in-sample observations. Our results are robust in both cases.

${ }^{7}$ It should be noted that the coefficients of friend's pregnancy outcomes, other than the focus pregnancy $t$, are not well identified in our model, for two reasons. First, our exclusion of friend's pregnancies that occur after the ego's pregnancy creates an artificial negative correlation between the ego's fertility outcomes and the number of her alters' pregnancies that are included in the sample. As a result, the positive coefficient of a friend's fertility outcome on the probability of the ego not having a pregnancy is likely to simply be a reflection of this artificial negative correlation between the ego's own fertility and the number of her friend's pregnancies included in the sample. Second, these coefficients are also confounded by unobserved heterogeneity in selection, which could explain why there appears to be no effect of friends' abortions and births on own fertility (that is, the artificial negative correlation is offset by positive selection on abortions and births - but not miscarriages suggesting those are plausibly random). These variables are included only as controls for the alter's fertility history so that our main coefficients of interest are not confounded by these effects. An approach that might help alleviate some of this confounding would be including all of the friends' pregnancies, even the ones that occurred after the ego's pregnancy, as controls in the regression. When we do this, the coefficients of the friends' past and future fertility outcomes on likelihood of ego's pregnancy and childbirth do become all positive and consistent with selection on unobservables, while the 
Our main set of results in Table 3 provides little evidence that, conditional on aggregate school-level fertility measures and other controls, miscarriages may be caused by exposure to shared environment or otherwise positively correlated among friends through unobserved selection. In particular, if friends' miscarriages were correlated (either through unobserved environmental factors or due to peer selection), we would expect a significant association between own and friend's likelihood of miscarriage. Furthermore, we find the association between own miscarriage and a friend's abortion, which could arise if friends' miscarriages were contaminated with abortions, to be non-significant. However, we will continue to examine the issue of potential contamination of miscarriages with abortions when we exploit the timing of friend's pregnancy resolution below.

Given that the overall prevalence of teen childbirth in the full sample is $13 \%$, the magnitude of the peer influence estimate in Table 3, 6.2 percentage points, represents a nontrivial effect. Recall that our identification strategy requires that we focus on peer influences received only from a relatively small proportion of an individual's full reference peer group, i.e. only pregnant friends who either gave birth or miscarried. This slightly complicates traditional estimates of social multiplier effects, as not everyone in the peer group is captured in our estimated peer effect. In typical linear-in-means models the assumption of large groups allows the straightforward calculation of the social multiplier as 1/(1- $\alpha)$ (Glaeser et al. 2003). In our case, we need to scale the $\alpha$ parameter by the proportion of pregnancies in our data $(\sim 20 \%)$. This produces a scaled-up peer effect of -0.31 and implies that if one friend's teen childbirth were

coefficients of the main identifying event (friend's miscarriage) remain unaffected. Results are available upon request. 
removed from the peer group, the overall reduction in teen childbearing would be $0.76^{8}$ cases, thus suggesting a non-trivial policy dampening effect.

The above computation of the social multiplier assumes that our peer influence estimate from the pregnant peer sample is generalizable to the full sample of all women, which may not be the case if our sample selection restriction of having a friend with a teen pregnancy was correlated with the underlying unobserved susceptibility to peer influence. For example, if women who did not have any pregnant friend are less likely to be influenced by their friend, we expect that the peer effect will be smaller in the non-pregnant friend group. In Table 4, we test whether some of the variables that may be indicative of susceptibility to peer influence differ between our sample of women with a pregnant friend and women who were excluded from the analysis because none of their friends had a teen pregnancy. ${ }^{9}$ We find little evidence that women in our sample may be more likely to be influenced by the peers. On the contrary, they are significantly less likely to feel that their friends care about them, and their parents are significantly less likely to report that these women are influenced by their friends. Although there are no differences in the amount of friend interactions, women in our sample are also slightly less likely to discuss problems with their friends. These results provide some suggestive evidence that peer influence in the full reference peer group may be at least as large as what we find in our sample, suggesting that our social multiplier estimate may be a lower bound.

\section{Robustness}

In order to further examine the robustness of the results from our preferred specifications in Table 3, we also examine two variations of our model. We first apply a "falsification test" to

${ }^{8} 1 /[1-(-0.31)]=0.76$.

${ }^{9}$ See Appendix $\mathrm{C}$ for the list of Add Health questions and description of the variables. 
ask whether future peer actions predict own behaviors and then we focus on the issue of potential contamination of miscarriages with abortions. In Table 5, we present estimation results for a chronologically incorrect model, where we regress own fertility outcomes on friend's subsequent pregnancy resolutions. We find that none of the own fertility outcomes are significantly associated with the friend's future fertility events. ${ }^{10}$

In Table 6, we examine the issue that an unknown portion of miscarriages are either misreported abortions, or, even if they are truly random, may not have resulted in childbirth but would instead become elective abortions. As we discuss earlier, the presence of abortions in the friend's miscarriage group could bias the estimated peer effect upward, or in our case because the coefficient estimate is negative, it may be biased toward zero. We attempt to test this by restricting our miscarriage instrument to include only miscarriages that occurred after the $8^{\text {th }}$, $10^{\text {th }}$, and $14^{\text {th }}$ week of pregnancy. We find that the estimates do increase in magnitude slightly as the gestational period increases, and are robust overall.

We also examine the robustness of the model to including different sets of controls and clustering at the level of the school, grade, individuals, and friendship dyad (online supplementary materials, Appendix E, Table 13). We find that the estimates are robust, even in the simplest model that does not include any controls, and consistent with a negative effect of peer childbirth on own teen childbearing.

\section{Mechanisms}

We attempt to explore the mechanism of peer influence by examining whether the magnitude of the effect varies depending on school-level fertility rates. If the negative effect

\footnotetext{
${ }^{10}$ The findings are also robust to eliminating all pregnancies that occurred prior to friendship nominations. Results are available upon request.
} 
arises through the learning mechanism, we would expect it to be larger in schools with low teen childbearing rates because the incremental amount of information learned from a friend's childbirth should increase with less exposure to teen childbirth at the school level. In Table 7, we interact friend's fertility variables with an indicator for above-average school-level teen childbearing rates $(>20 \%)$. Consistent with the learning mechanism, we find that the reduction in own chances of teen pregnancy and childbirth following a friend's childbirth is indeed larger in schools with low rates of teen childbearing (10.4 percentage points, $\mathrm{p}<.05$, vs. 5.2 percentage points, $\mathrm{p}>0.50$ ). This finding that the learning effect may be diminished with greater exposure to peer fertility also suggests that the magnitude of the effect of a friend's teen childbirth in the full reference peer group (i.e. including those not in our analysis sample) may be larger than is suggested by our estimates obtained on a pregnant friend sample. This is because the full reference group includes women who are not exposed to teen childbirth among their friends and who, therefore, may stand to learn the most from a peer's teen childbearing experience.

Similarly, we expect that women who themselves had a childbirth should not learn as much from their peers' childbearing experiences as women with no prior first-hand childbearing knowledge. Because there are only 90 such women in our sample (205 ego-alter events), we are unable to estimate the peer influence model for this small subgroup. However, consistent with the learning effect, excluding them does increase the magnitude of the friend's miscarriage effect on the likelihood of own childbirth $(0.068$, versus 0.062$)$ (online supplementary materials, Appendix E, Table 14). ${ }^{11}$

\footnotetext{
${ }^{11}$ The results are also robust when estimated on the subset of observations that only have one ego and one alter fertility event (see Appendix E, Table 13).
} 
To further explore learning as the potential mechanism of peer influence, we examine whether the magnitude of the effect changes depending on the characteristics of the friend's partner. We expect that if learning is the mechanism behind the negative peer effect, then the negative impact of a friend's teen childbirth should be smaller when the friend's partner is ready to assume the parenting role and thus alleviate the burden of childbearing compared to situation where the full burden falls on the teen mother herself, with little or no involvement from the partner. We use two survey questions in an attempt to gauge the propensity of the friend's partner toward participating in childrearing: one asks whether or not the respondent wanted their partner to be their child's parent, and the other one asks whether or not the partner accompanied the responded to pregnancy-related doctor/midwife/nurse appointments. The results are shown in Table 8 , and they are consistent with the idea that the negative peer effect in teen childbearing is larger when the childbearing experience of the friend is associated with more hardship. In particular, childbearing of peers who answered "no" to the questions about their partners has a large negative effect on own likelihood of teen pregnancy and childbearing, 12-14 percentage points $(\mathrm{p}<.05)$, as compared to women whose friends have a child with a partner who is ready to take on parenting responsibilities, 2 percentage points ( $\mathrm{p}>.50)$. The differences between these estimates are statistically significant at the .10 level. ${ }^{12}$

\footnotetext{
${ }^{12}$ An additional insight regarding the type of learning might be sought in examining the length of the friend's pregnancy at the time of miscarriage. If women are primarily learning about the difficulties of pregnancy versus the hardship of childrearing, we expect that the later the miscarriage is, the smaller will be the difference between the effects of a friend's miscarriage versus childbirth. However, the earlier examined estimates in Table 6 are suggesting a different pattern - in fact the effect of the miscarriage becomes larger as the gestational period increases.
} 
In Table 9 we utilize attitudes toward teen pregnancy and childbearing data provided in the Add Health data (Appendix D). ${ }^{13}$ The questions were asked during the in-home Wave I interview of respondents who were at least 15 years old at the time of the interview. ${ }^{14}$ The responses were recorded on a scale from "strongly disagree" to "strongly agree" and we define all attitudes variables as indicators for agreeing with a statement portraying pregnancy in a negative way. The results suggest that women whose friend had a teen birth are more likely to have a negative attitude toward teen pregnancy. They are significantly more likely to feel that pregnancy would be the worst thing to happen to them, that it would embarrass them, and could lead them to marry a wrong person. These findings also support the knowledge externalities model and the optimal behavioral rule under uncertainty. In particular, the estimates suggest that being friends with a teen mom is associated with increased perceptions of teen childbearing as being a negative outcome, and a tendency toward not repeating the friend's behavior.

\section{Limitations}

While our estimation methodology allows us to examine peer effects in adolescent childbearing using a plausibly exogenous source of variation, we would like to point out several

This may suggest that most of the learning is about the hardships of childrearing. However, as discussed above, this pattern of estimates might also be explained by the lower proportion of misreported and "would-be" abortions in the late miscarriage group.

13 "Motivations for Risky Behaviors" and "Attitudes toward Pregnancy, STD, and HIV" sections of the Wave I in-home questionnaire.

${ }^{14}$ The age restriction reduces the sample size in this sub-analysis by about one-third. Our main results are robust and in fact the magnitudes are larger in this older sub-sample. 
limitations to our methods and findings. The focus of the study was peer influences in childbirth, and the study design did not allow examination of how a woman's fertility may be influenced by other behaviors of friends (i.e. sexual behaviors and pregnancy). Similarly to most peer effects studies, we use "ever" measures and are unable to explore dynamic effects and time structure of peer influences explicitly. Using miscarriage as an instrument for (a lack of) childbirth assumes that a friend's miscarriage itself has little effect or is unknown to the ego, which may not always be the case. Because we use pregnancy histories collected retrospectively several years after many of the reported pregnancies occurred, recall bias may be an issue. The fact that less than $20 \%$ of the original in-school sample were followed through to Wave III resulted in incomplete capture of friendship networks ${ }^{15}$. Lastly, by selecting only individuals with friends who experienced a teen pregnancy, our sample may not be representative of the full high school population and the results may not generalize to other populations.

\section{Conclusion}

Our findings support the presence of a sizable negative local treatment effect on teen childbearing among close friends. Multinomial logistic regression with controls for own and friend's fertility history, extensive set of socio-demographic controls, local peer network structure, and school-level fertility measures suggest that a friend's teen birth is associated with a 6 percentage point reduction in the likelihood of own teen pregnancy and childbirth. There is

\footnotetext{
${ }^{15}$ Recall that Add Health by design only collected longitudinal data on 20,000 of the original 90,000 individuals who participated in the in-school survey. However, those followed were a random subset of the original 90,000 sampling frame.
} 
also evidence that this effect operates through a learning mechanism by changing attitudes toward early childbearing and reducing unwanted pregnancies.

The findings suggest that lowering the rates of teen motherhood could have an unintended spill-over effect of reducing a teen's exposure to peer childbearing and therefore limiting opportunities to learn from peer experiences. If similar learning mechanisms are operative in other teen decisions (e.g. alcohol use, drug use), our results may point to a general phenomenon that should be considered when designing policies to reduce certain teen behaviors. As effective targeted policies lower rates of teenage childbearing, reductions in the opportunities for social learning within networks may partially counteract the effects of the policy. More comprehensive approaches may be able to both reduce individual teen childbearing outcomes as well as provide information to peers about the consequences of teen childbearing in order to further reduce this outcome among teens.

Acknowledgments: Yakusheva thanks AHRQ for funding support from the T-32 Postdoctoral Training Grant in Health Services Research (5 T32 HS 17589-4). Fletcher thanks the Robert Wood Johnson Foundation Health \& Society Scholars program and the NICHD (1R21HD066230) for its financial support. We thank John Cawley, Lisa Kahn, Kandice Kapinos, Costas Meghir, Stephen Ross, Mark Schlesinger, Jody Sindelar, and seminar participants at the Macmillan Center for International and Area Studies, the Economics Labor Lunch, Yale Health Economics Workshop, and the Health Policy and Administration Seminar at Yale University, the Institute for Research on Poverty at the University of Wisconsin-Madison, 
and the Department of Policy Analysis and Management Seminar at Cornell University. Yakusheva thanks Emily Lephardt for research assistance in the early stages of the project.

This research uses data from Add Health, a program project directed by Kathleen Mullan Harris and designed by J. Richard Udry, Peter S. Bearman, and Kathleen Mullan Harris at the University of North Carolina at Chapel Hill, and funded by grant P01-HD31921 from the Eunice Kennedy Shriver National Institute of Child Health and Human Development, with cooperative funding from 23 other federal agencies and foundations. Special acknowledgment is due Ronald R. Rindfuss and Barbara Entwisle for assistance in the original design. Information on how to obtain the Add Health data files is available on the Add Health website (http://www.cpc.unc.edu/addhealth). No direct support was received from grant P01-HD31921 for this analysis.

\section{References}

Ali, Mir and Debra S. Dwyer. 2011. "Estimating Peer Effects in Sexual Behavior Among Adolescents." Journal of Adolescence, 34: 183-190

American College of Obstetricians and Gynecologists (ACOG). 2011. Early Pregnancy Loss: Miscarriage and Molar Pregnancy. In FAQ090 Pregnancy. http://www.acog.org/ /media/For\%20Patients/faq090.pdf?dmc=1\&ts=20120228T111004 3046. Accessed on Nov 102011.

Angrist, Joshua and William Evans. 1996. "Schooling and Labor Market Consequences of the 1970 State Abortion Reforms," paper presented at the 1997 Population Association of American meetings, Washington, D.C. 
Ashcraft, Adam, and Kevin Lang. 2006. “The Consequences of Teenage Childbearing,” National Bureau of Economic Research, Working Paper No. 12485.

Sachiko Baba, Hiroyuki Noda, Masahiro Nakayama, Masako Waguri, Nobuaki Mitsuda and Hiroyasu Iso. 2011. Risk factors of early spontaneous abortions among Japanese: a matched case-control study. Human Reproduction 26(2): 466-472

Banerjee, Abhijit V. 1992. "A Simple Model of Herd Behavior". Quarterly Journal of Economics 107 (3): 797-817. doi:10.2307/2118364.

Kohler, Hans-Peter, Jere R. Behrman and Susan C. Watkins. 2001. "The Density of Social Networks and Fertility Decisions: Evidence from South Nyanza District, Kenya", Demography, 38:43-58.

Bikhchandani, Sushil, David Hirshleifer and Ivo Welch. 1992. "A Theory of Fads, Fashion, Custom, and Cultural Change as Informational Cascades”, Journal of Political Economy, 100(5): 992-1026.

Bifulco, Robert, Jason M. Fletcher and Stephen L. Ross. 2011. "The Effect of Classmate Characteristics on Post-Secondary Outcomes: Evidence from the Add Health.” American Economic Journal: Economic Policy, 3(1): 25-53

Case, Ann and Lawrence Katz. 1991. "The company you keep: the effects of family and neighborhood on disadvantaged youth.” NBER Working Paper 3705.

Chevalier, Arnaud and Tarja K. Viitanen. 2003. "The long-run labour market consequences of teenage motherhood in Britain," Journal of Population Economics, Springer, 16(2): 323343.

Cramer, Daniel W. and Lauren Anne Wise. 2000. “The epidemiology of recurrent pregnancy loss," Seminars in Reproductive Medicine, 2000, 18(4):331-9. 
Department of Health and Human Services. 2009. Fiscal Year 2010 Budget in Brief. Report available at http://www.hhs.gov/asrt/ob/docbudget/2010BudgetInBrief.pdf

Eiben, Bernd, Iris Bartels, Susan Bähr-Porsch, Sabine Borgmann, Gudrun Gatz, Gaby Gellert, Richard Goebel, Wilhelm Hammans, Martha Hentemann, Rüdiger Osmers, Rüdiger Rauskolb, and Ingo Hansmann. 1990. "Cytogenetic Analysis of 750 Spontaneous Abortions with the Direct-Preparation Method of Chorionic Villi and Its Implications for Studying Genetic Causes of Pregnancy Wastage," American Journal of Human Genetics, 47: 656-663.

Evans, William N., Wallace E. Oates, and Robert M. Schwab. 1992. "Measuring Peer Group Effects: A Study of Teenage Behavior,” Journal of Political Economy, 100(5): 966-991.

Fletcher, Jason M. 2007. “Social Multipliers in Sexual Initiation Decisions among U.S. High School Students," Demography, 44 (2): 373-388.

Fletcher, Jason M. and Barbara L. Wolfe. 2009."Education and Labor Market Consequences of Teenage Childbearing: Evidence Using the Timing of Pregnancy Outcomes and Community Fixed Effects," Journal of Human Resources, 44: 303-325.

Fletcher, Jason M. and Barbara L. Wolfe. "The Effects of Teenage Fatherhood on Early Outcomes." Economic Inquiry. In press.

Fletcher, Jason M. and Olga Yakusheva. 2012. "Peer Effects on Teenage Fertility: Social Transmission Mechanisms and Policy Recommendations" (Working paper)

Glaeser, Edward L., Bruce I. Sacerdote, and Jose A. Scheinkman. 2003. "The Social Multiplier," Journal of the European Economic Association, 1(2-3):345-353 
Guryan, Jonathan, Kroft, Kory and Matthew J. Notowidigdo. 2009. "Peer Effects in the Workplace: Evidence from Random Groupings in Professional Golf Tournaments.” American Economic Journals: Applied Economics, 1(4): 34-68.

Green, Rochelle S., Brian Malig, Gayle C. Windham, Laura Fenster, Bart Ostro and Shanna Swan. 2009.“Residential Exposure to Traffic and Spontaneous Abortion.” Environmental Health Perspectives 117(12): 1939-1944

Hammerslough, Charles R. 1992. "Estimating the probability of spontaneous abortion in the presence or induced abortion and vice versa.” Public Health Perspectives, 107(3): 269277

Harrison, Ayanna T., Lorrie Gavin and Philip A. Hastings. 2012. "Pregnancy Contraceptive Use Among Teens with Unintended Pregnancies Resulting in Live Births - Pregnancy Risk Assessment Monitoring System (PRAMS), 2004-2008.” Morbidity Mortality Weekly Report, 61(02); 25-29

Hensvik, Lena, Krogstad Asphjell, Magne and J. Peter Nilsson. 2011. "Businesses, Buddies and Babies: Fertility and Social Interactions at Work" (Working Paper)

Hoffman, Saul D. and Lauren S. Scher. 2008. "Consequences of teen childbearing for the life chances of children, 1979-2002.” In: Hoffman S, Maynard R, eds. Kids having kids: economic costs and social consequences of teen pregnancy. Washington, DC: The Urban Institute Press; 2008.

Hogge, W.Allen, Abigail L Byrnes, Mark C Lanasa and Urvashi Surti. 2003. "The clinical use of karyotyping spontaneous abortions.” American Journal of Obstetrics and Gynecology, 189(2):397-402. 
Hotz, V. Joseph, Charles Mullin, and Seth Sanders. 1997. "Bounding Causal Effects Using Data from a Contaminated Natural Experiment: Analyzing the Effects of Teenage Childbearing." Review of Economic Studies 64(4):575-603.

Hotz, V. Joseph, McElroy, Susan Williams, and Seth G. Sanders. 2005. “Teenage Childbearing and Its Life Cycle Consequences.” Journal of Human Resources 40(3): 683-715

Jones, Rachel K. and Kathryn Kooistra. 2011. "Abortion incidence and access to services in the United States, 2008". Perspectives on Sexual and Reproductive Health. 43 (1): 41-50.

Kajii T, Ferrier A, Niikawa N, Takahara H, Ohama K, Avirachan S. 1980. “Anatomic and chromosomal anomalies in 639 spontaneous abortuses." Human Genetics, 55(1):87-98.

Kumar, Sunil. 2011. “Occupational, Environmental and Lifestyle Factors Associated With Spontaneous Abortion." Reproductive Sciences, 18(10):915-930

Kuziemko, Ilyana. 2006. “Is Having Babies Contagious? Estimating Fertility Peer Effects between Siblings." Working Paper

Lerner, Henry M. 2003. "Miscarriage: Why it happens and how best to reduce your risks." Perseus Publishing, 11 Cambridge Center, Cambridge, MA 02142.

Levine, David I. and Gary Painter. 2003. The schooling costs of teenage out-of-wedlock childbearing: Analysis with a within-school propensity-score-matching estimator. Review of Economics and Statistics 85(4): 884-900.

Manlove, Jennifer S., Elizabeth Terry-Humen, Lisa A. Mincieli and Kristen A. Moore. 2008. “Outcomes for children of teen mothers from kindergarten through adolescence." In: Hoffman S, Maynard R, eds. Kids having kids: economic costs and social consequences of teen pregnancy. Washington, DC: The Urban Institute Press; 2008. 
Manski, Charles. 1993. "Identification of endogenous social effects: the reflection problem." Review of Economic Studies 60(3): 531-542. . 1995. "Identification Problems in the Social Sciences.” Harvard University Press: Cambridge, MA. . 2000. "Economic analysis of social interactions." Journal of Economic Perspectives, 14: 3.

Martin, Joyce A., Brady E. Hamilton, Stephanie J. Ventura, Michelle J.K. Osterman, Sharon Kirmeyer, T.J. Mathews, and Elizabeth C. Wilson. 2010. "Births: Final Data for 2008," National Vital Statistics Reports, 59(1), Hyattsville, MD: U.S. Department of Health and Human Services.

_. 2011. "Births: Final data for 2009.” National Vital Statistics Reports, 60(1), Hyattsville, MD: U.S. Department of Health and Human Services.

Mathews, T.J. and Marian F. MacDorman. 2010. "Infant mortality statistics from the 2006 period linked birth/infant death data set.” National Vital Statistics Reports, 58(17). Hyattsville, MD: U.S. Department of Health and Human Services.

Matovina M, Husnjak K, Milutin N, Ciglar S, Grce M. 2004. "Possible role of bacterial and viral infections in miscarriages.” Fertility and Sterility, 81(3):662-9.

McDonald, Helen M. and Helen M. Chambers. 2000. "Intrauterine infection and spontaneous midgestation abortion: is the spectrum of microorganisms similar to that in preterm labor?" Infectious Diseases in Obstetrics and Gynecology, 8(5-6):220-7.

Monstad, Karin, Carol Propper and Salvanes, Kjell G. 2011. "Is teenage motherhood contagious? Evidence from a Natural Experiment,” CEPR Discussion Papers 8505, C.E.P.R. Discussion Papers. 
Montgomery, Mark R. and John B. Casterline. 1996. "Social Networks and the Diffusion of Fertility Control.” Policy Research Division Working Paper no. 119, New York: The Population Council.

Munshi, Kaivan and Jacques Myaux. 2006., "Social Norms and the Fertility Transition.” Journal of Development Economics 80, pp. 1-38.

Oats, Jeremy and Suzanne Abraham. 1995. "Miscarriage and Abortion.” In: Oats, Jeremy and Suzanne Abraham, eds. Llewellyn-Jones Fundamentals of Obstetrics and Gynecology. London: Mosby; 1995, pp. 99-103.

Philipp T, Philipp K, Reiner A, Beer F, Kalousek DK. 2003. "Embryoscopic and cytogenetic analysis of 233 missed abortions: factors involved in the pathogenesis of developmental defects of early failed pregnancies." Human Reproduction, 18(8):1724-32.

Regan, Lesley and Raj Rai. 2000. "Epidemiology and the medical causes of miscarriage." Bailliere’s Best Practice \& Research Clinical Obstetrics \& Gynaecology, 14(5):839-54.

Richards-Shubik, Seth. 2011. "Peer Effects in Sexual Initiation: Separating Demand and Supply Mechanisms." Working Paper

Royal College of Obstetricians; Gynecologists Study Group on Early Pregnancy Loss. 1997. "Recommendations arising from the 33rd RCOG study group on early pregnancy loss." In: Grudzinskas JG, O’Brien PMS, eds. Problems in early pregnancy: advances in diagnosis and treatment. London: RCOG Press; 1997.

Schlag, Karl H. 1998. "Why Imitate, and If So, How? A Boundedly Rational Approach to Multiarmed Bandits" Journal of Economic Theory 78, 130-156

Michels, Thomas C. and Alvin Y. Tiu. 2007. "Second Trimester Pregnancy Loss.” American Family Physician. 76(9): 1341-1346. 
United Nations. 2010. 2008 Demographic Yearbook. New York, NY: United Nations; 2010.

U.S. Department of Health and Human Services. 2004. "The Health Consequences of Smoking: A Report of the Surgeon General.” Atlanta: U.S. Department of Health and Human Services, Centers for Disease Control and Prevention, National Center for Chronic Disease Prevention and Health Promotion, Office on Smoking and Health.

Venners, Scott A., Xiaobin Wang, Changzhong Chen, Lihua Wang, Dafang Chen, Wenwei Guang, Aiqun Huang, Louise Ryan, John O’Connor, Bill Lasley, James Overstreet, Allen Wilcox and Xiping Xu. 2004. "Paternal smoking and pregnancy loss: a prospective study using a biomarker of pregnancy." American Journal of Epidemiology 159 (10): 9931001.

Yakusheva, Olga, Kandice Kapinos and Marianne Weiss. 2011. "Peer Effects and the Freshman 15: Evidence from a Natural Experiment.” Economics and Human Biology, 9(2):119132.

Yakusheva, Olga, Kandice Kapinos and Daniel Eisenberg. "Estimating Heterogeneous and Hierarchical Peer Influences on Body Weight Using Roommate Assignment as a Natural Experiment." Forthcoming in Journal of Human Resources. 
$\underline{\text { Tables }}$

Table 1. Descriptive statistics, by exposure to friend pregnancy

Final sample:

$\begin{array}{ccc}\text { Pregnant Alter }= & \text { Pregnant Alter }= & \text { Pregnant Alter }= \\ \text { No, } & \text { Yes, } & \text { Yes, }\end{array}$

\begin{tabular}{|c|c|c|c|}
\hline & $\mathrm{N}=1592$ & $\mathrm{~N}=838$ & $\mathrm{~N}=775$ \\
\hline Had a pregnancy & $0.15^{* * *}$ & 0.24 & 0.18 \\
\hline Had a miscarriage & $0.02 * * *$ & 0.03 & 0.03 \\
\hline Had an abortion & 0.03 & 0.04 & 0.03 \\
\hline Had a birth & $0.10 * * *$ & 0.16 & 0.12 \\
\hline Age & 16.13 & 16.08 & 16.08 \\
\hline African American & $0.14 * * *$ & 0.27 & 0.26 \\
\hline White & $0.78 * * *$ & 0.66 & 0.67 \\
\hline Asian & $0.03 * * *$ & 0.02 & 0.02 \\
\hline Hispanic Ethnicity & 0.04 & 0.05 & 0.05 \\
\hline Held back in grades $1-5$ & $0.09 * * *$ & 0.14 & 0.14 \\
\hline Suburban residence & $0.34 * * *$ & 0.25 & 0.25 \\
\hline Rural residence & $0.37 * * *$ & 0.44 & 0.45 \\
\hline Two-parent household & $0.77 * * *$ & 0.70 & 0.70 \\
\hline \multicolumn{4}{|l|}{ Annual family income, } \\
\hline$\$ 10,000$ & $5.10 * * *$ & 3.52 & 3.53 \\
\hline Number of siblings & 1.34 & 1.32 & 1.32 \\
\hline Birth order & 1.80 & 1.81 & 1.83 \\
\hline
\end{tabular}


Mother born in USA

Mother ever smoked

Mother's education

Number of friend

nominations

Average friendship rank

Reciprocal nomination

Sch. avg. teen preg. rate

Sch. avg. teen misc. rate

Sch. avg. teen abort. rate

Sch. avg. teen birth rate

Sch. avg. African
$4.52 * * *$

2.66

$0.53 *$

$0.20 * * *$

$0.04 * * *$

$0.04 * * *$

$0.15 * * *$

0.20
$0.18 * * *$

0.26

0.26

Sch. avg. mother's

education

Sch. avg. family income

Sch. avg. two-parent

household

$0.75 * * *$

0.70

0.70

$* * * \mathrm{p}<.01, * * \mathrm{p}<.05, * \mathrm{p}<.10$ between columns (1) and (2). Column (2) includes 63 egos pregnant before any of the friends; Column (3) excludes such egos. Ego fertility rates in column (3) are lower because of this exclusion. None of the other characteristics in Column (3) are significantly different from Column (2). 
Table 2. Balancing tests, pregnant alter sample, $\mathrm{N}=1,490$

\section{Coefficient of alter's \\ miscarriage}

Std. Error

\begin{tabular}{|c|c|c|}
\hline Age & -0.244 & $(0.233)$ \\
\hline African American & -0.0384 & $(0.0475)$ \\
\hline White & 0.0285 & $(0.0482)$ \\
\hline Asian & 0.00751 & $(0.0163)$ \\
\hline Other race & 0.0223 & $(0.0229)$ \\
\hline Hispanic ethnicity & 0.0544 & $(0.0446)$ \\
\hline Held back in grades $1-5$ & -0.0177 & $(0.0370)$ \\
\hline Urban residence & 0.0352 & $(0.0500)$ \\
\hline Suburban residence & -0.0421 & $(0.0412)$ \\
\hline Two-parent family & -0.00157 & $(0.0507)$ \\
\hline Family income & 0.448 & $(0.489)$ \\
\hline Number of siblings & -0.125 & $(0.0998)$ \\
\hline Birth order & 1.177 & $(3.584)$ \\
\hline Mother's age & 0.639 & $(3.079)$ \\
\hline Mother born in USA & 0.0338 & $(0.0435)$ \\
\hline Mother smoked & 0.0313 & $(0.0466)$ \\
\hline Mother's education & 0.642 & $(0.537)$ \\
\hline \multicolumn{3}{|l|}{ Number of friend } \\
\hline nominations & -0.123 & $(0.161)$ \\
\hline Average friendship rank & 0.118 & $(0.132)$ \\
\hline
\end{tabular}


Reciprocated nomination

Sch. avg. teen preg. rate

Sch. avg. teen misc. rate

Sch. avg. teen abort. rate

Sch. avg. teen birth rate

Sch. avg. African Americans

Sch. avg. family income

Sch. avg. mother's education

Sch. avg. two-parent
$-0.137 * *$

(0.0369)

$-0.0131$

(0.0119)

$-0.00458$

$(0.00352)$

0.00908

$(0.00650)$

$-0.0188$

(0.0119)

0.0116

(0.0319)

0.119

$(0.200)$

0.128

$(0.140)$

household

0.00860

Shown are regression estimates of own characteristics on friend's miscarriage indicator (baseline is friend's teen birth, friend's abortions excluded), using the final sample of 1490 "own fertility outcome $\times$ friend's fertility outcome" observations. No other controls included. Estimates adjusted for survey design (including clustering at the school level, $\mathrm{n}=108$ ) and weighted using Add Health Core 1 weights combined with our inverse frequency weights; standard errors also adjusted for clustering at the individual level $(\mathrm{n}=775) . \quad * * * \mathrm{p}<.01, * * \mathrm{p}<.05, * \mathrm{p}<.1$ 
Table 3. Multinomial logistic regression results, pregnant alter sample, $\mathrm{N}=1490$
(1)
(2)
(3)
(4)

Ego i's fertility (no pregnancy/ miscarriage/ abortion/ birth), $\mathrm{t}+1$

No pregnancy Pregnancy resolution

VARIABLES

Miscarriage Abortion Birth

$\underline{\text { Alter j's focus fertility event, } t:}$

Miscarriage

$\begin{array}{llll}-0.0577 * & 0.00714 & -0.0118 & 0.0624 * * \\ (0.0324) & (0.0110) & (0.0252) & (0.0245)\end{array}$

Abortion

0.0134

0.00487

0.00166

$-0.0199$

$(0.0332)$

(0.0101)

(0.0190)

(0.0252)

Ego i's fertility controls before $\mathrm{t}+1$ :

Miscarriages

$\begin{array}{cccc}-0.124 * * * & 0.0231^{*} & 0.0280 & 0.0724 * * \\ (0.0418) & (0.0131) & (0.0171) & (0.0321)\end{array}$

Abortions

$-0.0578$

0.0284

0.0112

0.0182

$(0.0528)$

(0.0290)

$(0.0115)$

(0.0439)

Births

$\begin{array}{cccc}-0.102 * * * & 0.0151 * & 0.0185 & 0.0680 * * * \\ (0.0259) & (0.00845) & (0.0147) & (0.0205)\end{array}$

Alter j's other fertility controls:

Miscarriages

before $\mathrm{t}$

$$
0.0805^{*}
$$

$-0.0283^{*}$

$-0.0197$

$-0.0325$

(0.0466)

(0.0150)

(0.0303)

(0.0280)

Miscarriages

$0.230 * * *$

$0.0207 * *$

$-0.304 * * *$

$0.0536 * * *$ 
between $t$ and $t+1$

$\begin{array}{lcccc} & (0.0498) & (0.00957) & (0.0505) & (0.0186) \\ \text { Abortions before t } & -0.00844 & 0.00397 & 0.00911^{* *} & -0.00464 \\ & (0.0363) & (0.00887) & (0.00441) & (0.0356)\end{array}$

Abortions between

$\mathrm{t}$ and $\mathrm{t}+1$

$-0.00981$

$-0.0351^{*}$

0.0129

0.0320

(0.0396)

(0.0211)

(0.00828)

(0.0398)

Births before $\mathrm{t}$

$-0.0463 * * *$

$0.0117 * *$

0.0126

0.0220

(0.0160)

$(0.00581)$

(0.0126)

(0.0137)

Births between $\mathrm{t}$

and $\mathrm{t}+1$

$-0.00396$

0.00485

$-0.0189$

0.0180

(0.0241)

(0.00648)

(0.0173)

(0.0191)

Other friends' fertility controls before $\mathrm{t}+1$ :

$\begin{array}{lcccr}\text { Miscarriages } & 0.0420 & -0.0206 & -0.0145 & -0.00683 \\ & (0.0717) & (0.0213) & (0.0309) & (0.0550) \\ \text { Abortions } & -0.101 & -0.0348 & 0.0998 * * * & 0.0363 \\ & (0.0691) & (0.0284) & (0.0201) & (0.0557) \\ \text { Births } & -0.0496 & 0.000938 & -0.0507 & 0.0994 * * * \\ & (0.0467) & (0.0177) & (0.0398) & (0.0265)\end{array}$

Friendship controls:

Friend Nomination

Rank: \#2

$\begin{array}{ll}0.0106 & -0.00846 \\ (0.0297) & (0.0100)\end{array}$

$-0.0296$

0.0274

$(0.0203)$

(0.0249) 
Friend Nomination

Rank: \#3
0.00372
$-0.0142$
$-0.0234$
0.0338
(0.0318)
(0.0115)
$(0.0165)$
(0.0258)

Friend Nomination

Rank: \#4

$\begin{array}{llll}0.0449 & -0.0214 & -0.0266 & 0.00306 \\ (0.0403) & (0.0145) & (0.0212) & (0.0279)\end{array}$

Friend Nomination

Rank: \#5

$$
0.0689 *
$$

$-0.0298 * *$

$-0.0226$

$-0.0165$

(0.0374)

(0.0143)

(0.0174)

(0.0292)

Number of

nominations

$\begin{array}{llll}-0.0141 * * & 0.00219 & 0.00716^{* *} & 0.00478 \\ (0.00635) & (0.00316) & (0.00298) & (0.00586)\end{array}$

Reciprocated

nomination

$$
0.0437 *
$$

$-0.0139 * *$

$-0.00832$

$-0.0215$

$(0.0235)$

(0.00701)

(0.0135)

(0.0203)

Ego i's controls:

$\begin{array}{lcccc}\text { African American } & -0.0306 & 0.0270^{* *} & -0.00643 & 0.00998 \\ & (0.0384) & (0.0129) & (0.0249) & (0.0254) \\ \text { Asian } & 0.177 * & -0.283 * * * & 0.0440^{*} & 0.0620 \\ & (0.0970) & (0.0907) & (0.0253) & (0.0412) \\ & -0.0362 & -0.00426 & 0.0216 & 0.0189 \\ \text { Other Race } & (0.0475) & (0.0277) & (0.0194) & (0.0449) \\ & -0.0452 & -0.00738 & 0.0116 & 0.0410\end{array}$




$\begin{array}{llll}(0.0492) & (0.0213) & (0.0281) & (0.0322)\end{array}$

Age in years

$\begin{array}{llll}0.0246 * * * & -0.00478 * * & -0.00532 & -0.0145 * * \\ (0.00829) & (0.00234) & (0.00428) & (0.00644)\end{array}$

Held back in

grades $1-5$

$\begin{array}{llll}-0.0250 & 0.0104 & -0.0245 & 0.0392 \\ (0.0287) & (0.0116) & (0.0184) & (0.0241)\end{array}$

Two-parent family

$-0.00694$

0.00734

$-0.0147$

0.0143

(0.0275)

(0.0161)

(0.0117)

(0.0266)

Family income

$-0.000449$

$-5.22 \mathrm{e}-06$

$0.00122 *$

$-0.000762$

(0.00139)

(0.000675)

(0.000633)

(0.00118)

Number of

siblings

$\begin{array}{llll}0.0146 & 0.00421 & -0.00665 & -0.0122 \\ (0.00961) & (0.00409) & (0.00501) & (0.00852)\end{array}$

Birth order

$-0.00701$

$-0.00204$

0.000239

0.00880

(0.0108)

(0.00565)

(0.00621)

(0.00886)

Mother's age

$0.00321 *$

$-0.000423$

$-0.000910 * *$

$-0.00188$

(0.00171)

(0.000628)

$(0.000451)$

(0.00119)

Mother's education

0.000142

0.000220

0.00169

$-0.00205$

(0.00370)

(0.00171)

(0.00169)

$(0.00288)$

Mother smoked

$$
-0.0175
$$

0.00289

$-0.00718$

0.0218

(0.0223)

(0.0100)

(0.0147)

(0.0202)

Mother born in

USA

$-0.129 * *$

$0.0215^{*}$

0.00847

$0.0994 *$ 
Suburban

$\begin{array}{lcccc}\text { residence } & -0.00603 & -0.00799 & -0.00422 & 0.0182 \\ & (0.0343) & (0.0144) & (0.0135) & (0.0310) \\ \text { Rural residence } & 0.0143 & 0.00661 & -0.0269 & 0.00602 \\ & (0.0301) & (0.0110) & (0.0199) & (0.0273)\end{array}$

$\underline{\text { School-level controls: }}$

Sch. avg. mother's

education

$\begin{array}{llll}0.0402 & -0.0465^{* *} & -0.00438 & 0.0107 \\ (0.0534) & (0.0222) & (0.0387) & (0.0397)\end{array}$

Sch. avg. family

income

$\begin{array}{llll}0.0117 & -0.00535 * * & -0.00328 & -0.00305 \\ (0.00719) & (0.00272) & (0.00344) & (0.00764)\end{array}$

Sch. Avg. African

Americans

$$
\begin{array}{cccc}
-0.0392 * * * & 0.0176 * * * & 0.00196 & 0.0196 * \\
(0.0131) & (0.00563) & (0.00767) & (0.0102)
\end{array}
$$

Urban school

$-0.0181$

0.0103

$-0.00777$

0.0156

(0.0449)

(0.0292)

(0.0220)

(0.0426)

Sch. avg. teen

misc. rage

$\begin{array}{llll}-0.431 & 0.224 & 0.0707 & 0.137 \\ (0.415) & (0.141) & (0.215) & (0.338)\end{array}$

Sch. avg. teen

abort. rate

$-0.270$

$-0.0601$

$0.354 * *$

$-0.0248$ 
Sch. avg. teen

birth rate

$$
-0.448 * *
$$

$0.118 *$

$-0.0792$

$0.409 * * *$

(0.187)

(0.0614)

(0.113)

(0.145)

Shown are average marginal effects from a multinomial logistic regression of own fertility outcome on prior friend's fertility outcome for the pregnant friend sample (Model 1). Estimates adjusted for survey design (including clustering at the school level, $n=108$ ) and weighted using Add Health Core 1 weights combined with our inverse frequency weights; standard errors also adjusted for clustering at the individual level $(\mathrm{n}=775)$. Standard errors in parentheses. $* * * \mathrm{p}<0.01, * * \mathrm{p}<0.05, * \mathrm{p}<0.1$ 
Table 4. Differences in measures of susceptibility to peer influence by exposure to friends' fertility, $N=2,430$

\begin{tabular}{lcc}
\hline VARIABLES & Coefficient of INSAMPLE & Std. Error \\
\hline Friends care about me & $-0.0815^{* *}$ & $(0.0318)$ \\
Influenced by friends & $-0.0696^{* * *}$ & $(0.0205)$ \\
Hang out with friends & 0.0297 & $(0.0426)$ \\
Go to friend's house & 0.0263 & $(0.0214)$ \\
See friend after school & 0.0252 & $(0.0210)$ \\
See friend on weekends & 0.00337 & $(0.0212)$ \\
Discuss problems with friend & $-0.0155^{*}$ & $(0.0092)$
\end{tabular}

Shown are regression estimates of friendship characteristics on an indicator for having at least one friend with a teen pregnancy (INSAMPLE $=1$, if in the pregnant friend sample; $=0$ otherwise). Included are all 2,430 women matched with a friend, omitted category are women with no pregnant friends. No other controls included. Estimates adjusted for survey design (including clustering at the school level) and weighted using Add Health Core 1 weights combined with our inverse frequency weights; standard errors also adjusted for clustering at the individual level. $* * * \mathrm{p}<.01, * * \mathrm{p}<.05, * \mathrm{p}<.1$ 
Table 5. Results for chronologically incorrect peer effects, $\mathrm{N}=1551$
(1)
(2)
(3)

(4)

No pregnancy

Pregnancy resolution

VARIABLES

Miscarriage Abortion Birth

Alter's miscarriage

$-0.000822$

$-0.0283$

0.0214

0.00778

$(0.0386)$

$(0.0186)$

(0.0170)

(0.02290)

Shown are average marginal effects from a multinomial logistic regression of own fertility outcome on subsequent friend's fertility outcome for the pregnant friend sample. Other controls (not shown) are same as in table 3. Estimates adjusted for survey design (including clustering at the school level) and weighted using Add Health Core 1 weights combined with our inverse frequency weights; standard errors also adjusted for clustering at the individual level. Standard errors in parentheses. $* * *$ $\mathrm{p}<0.01, * * \mathrm{p}<0.05, * \mathrm{p}<0.1$ 
Table 6. Results after excluding all friend's abortions and early miscarriages.

$>8$ weeks

Variables

\begin{tabular}{cl}
\hline No & Miscarr Ab \\
pregnan & iage
\end{tabular}

cy

n
$>10$ weeks

$\begin{array}{ccr}\text { No } & \text { Miscarr } & \text { Abortio } \\ \text { pregnanc } & \text { iage } & \mathrm{n} \\ \mathrm{y} & & \end{array}$

$>14$ weeks

$\begin{array}{cccc}\text { No } & \text { Miscar } & \text { Abortio } & \text { Birth } \\ \text { pregnan } & \text { riage } & n & \\ \text { cy } & & & \end{array}$

$\begin{array}{lccccccccccccccc}\text { Alter's } & -0.068 * * & 0.014 & 0.001 & 0.053 * & -0.090 * * & -0.003 & 0.023 & 0.070 * * & -0.096 * * & 0.0003 & 0.023 & 0.073 * * \\ \text { miscarriage } & & & & & & & & & & & & & & & \\ & (0.029) & (0.014) & (0.020) & (0.029) & (0.044) & (0.023) & (0.030) & (0.034) & (0.043) & (0.022) & (0.032) & (0.034)\end{array}$

Obs

Shown are average marginal effects from a multinomial logistic regression of own fertility outcome on prior friend's fertility outcome for the pregnant friend sample, excluding all friends' abortions and early miscarriages. Other controls (not shown) are same as in table 3. Estimates adjusted for survey design (including clustering at the school level) and weighted using Add Health Core 1 weights combined with our inverse frequency weights; standard errors also adjusted for clustering at the individual level. Standard errors in parentheses. $* * * \mathrm{p}<0.01, * * \mathrm{p}<0.05, *$ 
$\mathrm{p}<0.1$ 
Table 7. Differences in predicted probabilities of own fertility by friend's miscarriage status and school-level exposure to teen childbearing, $\mathrm{N}=1,409$.

\begin{tabular}{|c|c|c|c|c|c|c|c|c|}
\hline & \multicolumn{4}{|c|}{ School with high teen birth rate } & \multicolumn{4}{|c|}{ School with low teen birth rate } \\
\hline & $\begin{array}{c}\text { No } \\
\text { pregnancy }\end{array}$ & Miscarriage & Abortion & Birth & $\begin{array}{c}\text { No } \\
\text { pregnancy }\end{array}$ & Miscarriage & Abortion & Birth \\
\hline $\mathrm{P}(\mathrm{Y} \mid$ Alter's misc. = No $)$ & 0.852 & 0.0226 & 0.0415 & 0.0837 & 0.859 & 0.0220 & 0.0285 & 0.0909 \\
\hline $\mathrm{P}(\mathrm{Y} \mid$ Alter's misc. $=\mathrm{Yes})$ & 0.823 & 0.0408 & $7.10 \mathrm{e}-08$ & 0.136 & 0.758 & 0.0200 & 0.0275 & 0.195 \\
\hline$\Delta=\mathrm{P}(\mathrm{Y} \mid \mathrm{Y}$ es $)-\mathrm{P}(\mathrm{Y} \mid \mathrm{No})$ & -0.0290 & 0.0182 & $-0.0415^{*}$ & 0.0523 & $-0.1010 *$ & -0.0020 & -0.0010 & $0.1041^{* *}$ \\
\hline F-statistic of $\Delta$ & 0.31 & 0.50 & 2.78 & 0.27 & 3.45 & 0.03 & 0.00 & 4.02 \\
\hline \multicolumn{9}{|c|}{ Predicted probabilities are obtained from an extension of model (1) that includes an interaction term between friend's } \\
\hline \multicolumn{9}{|c|}{ alone term for being from such school. Estimates adjusted for survey design (including clustering at the school level, $\mathrm{n}=108$ ) } \\
\hline and weighted using Add $\mathrm{H}$ & ealth Core $1 v$ & veights comb & ned with 0 & inverse & juency weig & hts; standard e & rrors also a & idjusted \\
\hline
\end{tabular}


the significance test of the difference being equal to zero. $* * * p<0.01, * * p<0.05, * p<0.1$ 
Table 8. Differences in predicted probabilities of own fertility by alter's miscarriage status and alter's view of her partner

\begin{tabular}{|c|c|c|c|c|c|c|c|c|}
\hline & \multicolumn{4}{|c|}{ Bad partner $=0$} & \multicolumn{4}{|c|}{ Bad partner $=1$} \\
\hline & $\begin{array}{c}\text { No } \\
\text { pregnancy }\end{array}$ & Miscarriage & Abortion & Birth & $\begin{array}{c}\text { No } \\
\text { pregnancy }\end{array}$ & Miscarriage & Abortion & Birth \\
\hline \multicolumn{9}{|c|}{ Did friend want partner to be their child's parent? (Bad Partner $=1$, if "No") } \\
\hline $\mathrm{P}(\mathrm{Y} \mid$ Alter's misc. $=\mathrm{No})$ & 0.869 & 0.0198 & 0.0242 & 0.0870 & 0.847 & 0.0259 & 0.0415 & 0.0858 \\
\hline $\mathrm{P}(\mathrm{Y} \mid$ Alter's misc. $=$ Yes $)$ & 0.855 & 0.0366 & $7.24 \mathrm{e}-08$ & 0.108 & 0.724 & 0.0237 & 0.0313 & 0.221 \\
\hline$\Delta=\mathrm{P}(\mathrm{Y} \mid \mathrm{Yes})-\mathrm{P}(\mathrm{Y} \mid \mathrm{No})$ & -0.0140 & 0.0168 & -0.024 & 0.0210 & $-0.123 * * \dagger$ & -0.0022 & -0.0102 & $0.135 * * * \dagger$ \\
\hline F-statistic & 0.12 & 0.51 & 2.96 & 0.29 & 5.35 & 0.02 & 0.15 & 7.87 \\
\hline \multicolumn{9}{|c|}{ Did friend's partner go along to pregnancy-related doctor's visits? (Bad Partner $=1$, if "No") } \\
\hline $\mathrm{P}(\mathrm{Y} \mid$ Alter's misc. $=\mathrm{No})$ & 0.864 & 0.0174 & 0.0266 & 0.0918 & 0.853 & 0.0295 & 0.0395 & 0.0778 \\
\hline $\mathrm{P}(\mathrm{Y} \mid$ Alter's misc. $=$ Yes $)$ & 0.849 & 0.0380 & $8.09 \mathrm{e}-08$ & 0.113 & 0.742 & 0.0233 & 0.0325 & 0.202 \\
\hline$\Delta=\mathrm{P}(\mathrm{Y} \mid \mathrm{Yes})-\mathrm{P}(\mathrm{Y} \mid \mathrm{No})$ & -0.0150 & 0.0206 & -0.027 & 0.0212 & $-0.111^{*}$ & -0.0062 & -.0070 & $0.124 * * \dagger$ \\
\hline F-statistic & 0.71 & 0.45 & 2.38 & 0.27 & 3.56 & 0.20 & 0.06 & 5.92 \\
\hline
\end{tabular}


Predicted probabilities are obtained from an extension of model (1) that includes an interaction term between friend's

miscarriage indicator and an indicator for friend answering "no" to the questions about their partner. Estimates adjusted for survey design (including clustering at the school level) and weighted using Add Health Core 1 weights combined with our inverse frequency weights; standard errors also adjusted for clustering at the individual level. The bottom two rows show the difference between the predicted probabilities of the corresponding own fertility outcome by friend's miscarriage status (relative to friend's birth), and the F-statistics of the significance test of the difference. *** $\mathrm{p}<0.01, * * \mathrm{p}<0.05, * \mathrm{p}<0.1 ; \dagger \mathrm{p}<.10$ show a significant second difference, $\left(\Delta^{\text {Bad Partner }=1}-\Delta^{\text {Bad Partner }=0}\right)$. 
Table 9. Own beliefs about pregnancy on friend's miscarriage

\begin{tabular}{|c|c|c|c|c|c|c|c|}
\hline & (1) & (2) & (3) & (4) & (5) & (6) & (7) \\
\hline & Pregnancy is & Pregnancy & Embarrass & Embarrass & & Marry & \\
\hline VARIABLES & worst thing & risk & family & self & Quit school & wrong & Grow up fast \\
\hline \multirow[t]{2}{*}{ Alter's miscarriage } & $-0.0705 * *$ & -0.0204 & 0.0133 & $-0.0436^{*}$ & 0.00886 & $-0.0711^{*}$ & -0.0339 \\
\hline & $(0.0342)$ & $(0.0460)$ & $(0.0571)$ & $(0.0263)$ & $(0.0453)$ & $(0.0416)$ & $(0.0547)$ \\
\hline Observations & 844 & 870 & 828 & 858 & 853 & 857 & 858 \\
\hline
\end{tabular}

Estimates are marginal effects from a binomial logistic model of the indicator for agreeing with a negative statement about pregnancy on

friend's teen pregnancy resolution modeled as in (1). Other controls (not shown) are same as in table 3. Estimates adjusted for survey design

(including clustering at the school level) and weighted using Add Health Core 1 weights combined with our inverse frequency weights;

standard errors also adjusted for clustering at the individual level. Standard errors in parentheses. $* * * \mathrm{p}<.01, * * \mathrm{p}<.05, * \mathrm{p}<.10$. 
Figures

Figure 1.A Miscarriages by week of gestation

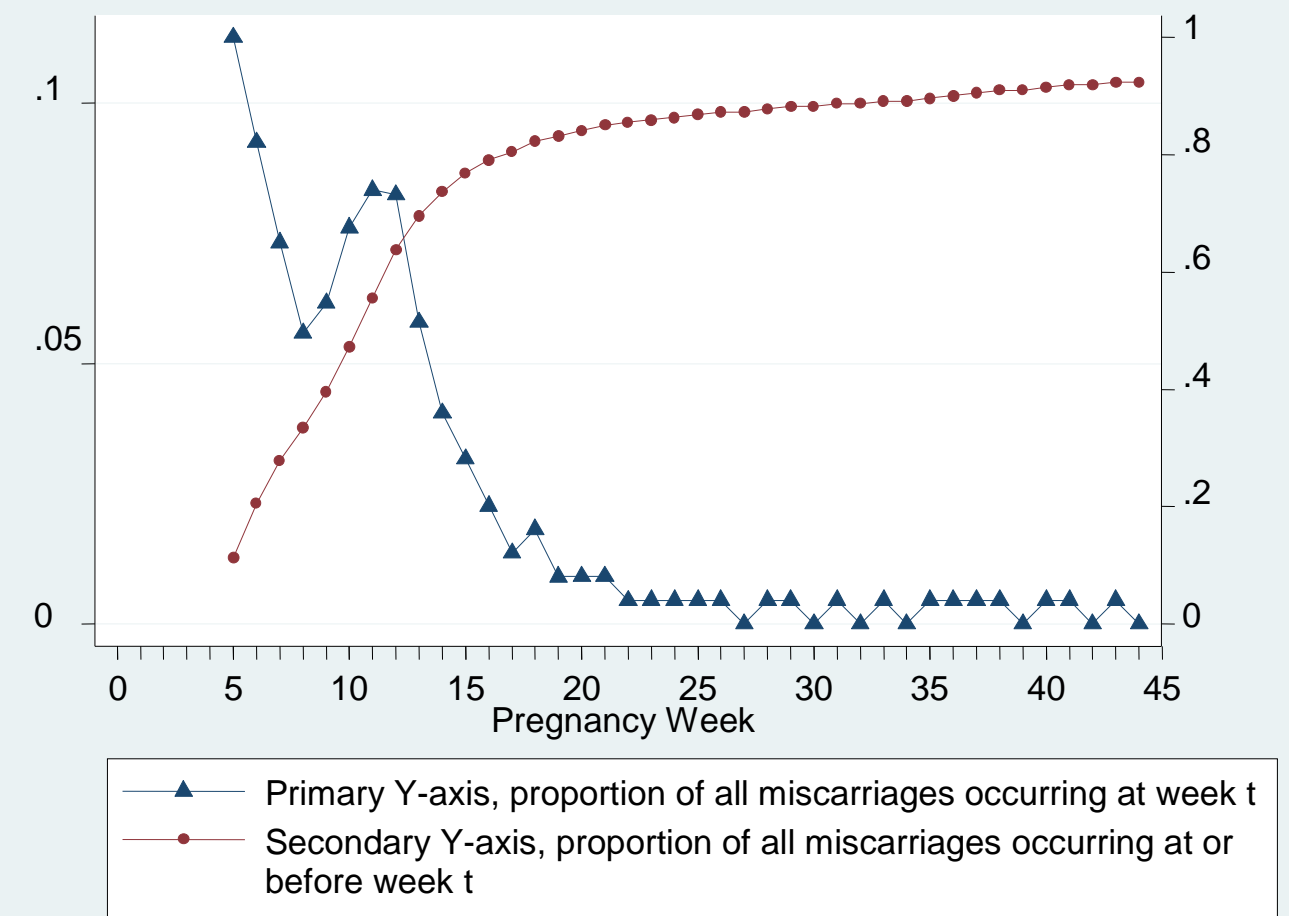

Adapted from Hammerslough (1992) 
Figure 1.B Abortions by week of gestation

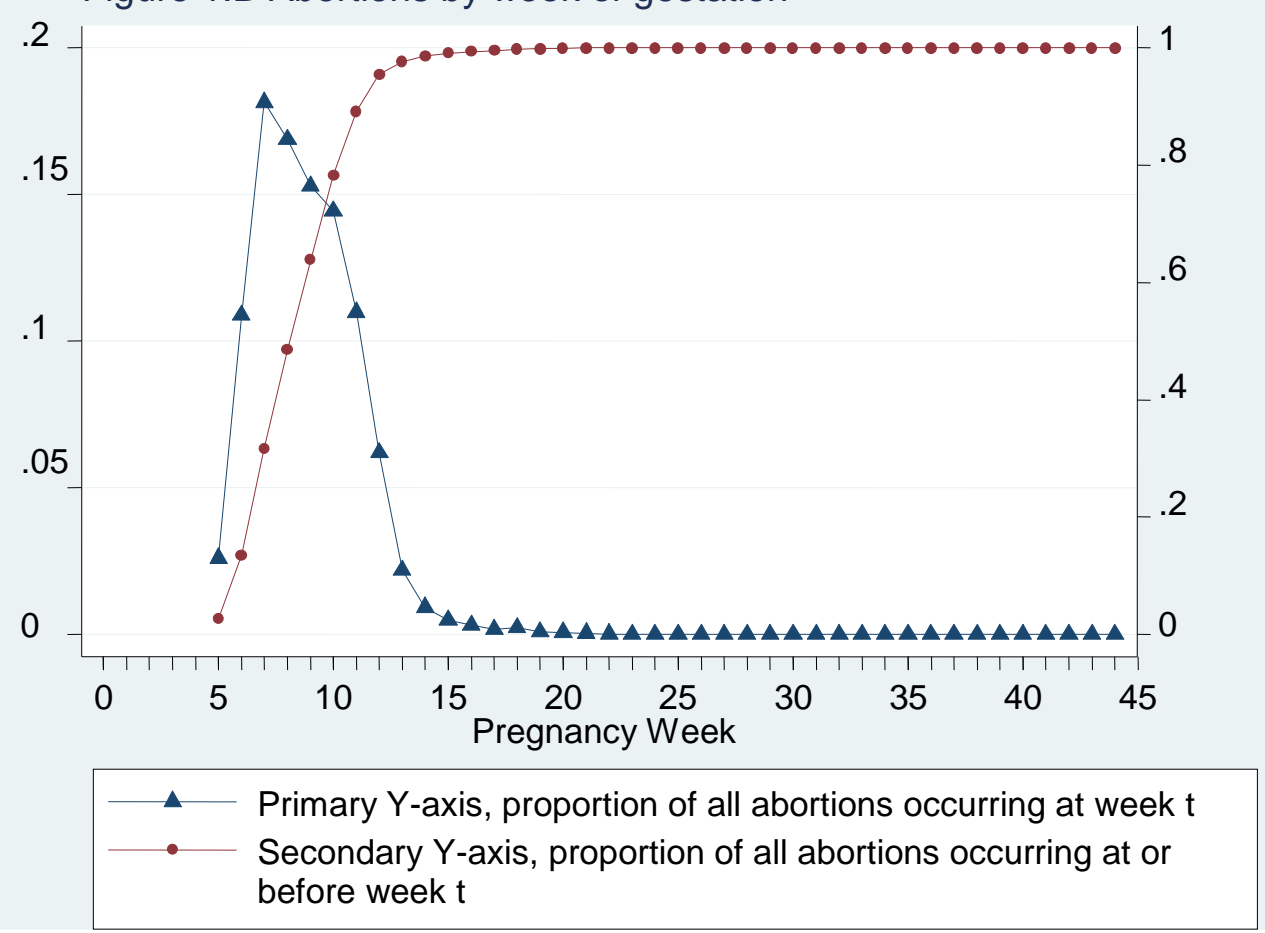

Adapted from Hammerslough (1992). 